\title{
Turbulence-Augmented Minimization of Combustion Time in Mesoscale Internal Combustion Engines
}

\author{
Yongxian $\mathrm{Gu}^{*}$ and Werner J.A. Dahm ${ }^{\dagger}$ \\ Laboratory for Turbulence and Combustion (LTC), Department of Aerospace Engineering
}

The University of Michigan, Ann Arbor, MI 48109

\begin{abstract}
Mesoscale internal combustion engines for a variety of new combustion system applications have dimensions that are far smaller than conventional macroscale engines, yet unlike true microscale engines allow significant mean flow and turbulence to be created in the combustion chamber by the injection process. The resulting flow allows minimization of the combustion time by augmenting flame propagation across the combustion chamber to provide maximum power and efficiency. However injection and ignition locations that give minimum combustion times in traditional macroscale engines are of limited relevance in such small-scale engines. This study has therefore examined premixed flame propagation in a generic mesoscale combustion chamber for various injection and ignition configurations to develop guidelines for minimizing combustion times in mesoscale engines. Numerical simulations based on the $G$-equation, coupled with mean flow and turbulence fields for various injection configurations, reveal key features of flame propagation and combustion times for combinations of injection and ignition sites. Mean flow velocities and turbulent flame speeds are found to be comparable in such mesoscale engines, indicating that both the mean flow and turbulence must be matched to the combustion chamber geometry to minimize the overall combustion time $\tau_{B}$. Results show that $\tau_{B}$ in such mesoscale engines can be 8-20 times faster than the laminar combustion time scale $L_{\max } / S_{L}^{0}$ that governs true microscale engines, and can be 1-2 times faster than the turbulent combustion time scale $L_{\max } / S_{L}^{0}$. Minimum $\tau_{B}$ values are found to result from injection across the smallest chamber dimension, with ignition on the opposite side of the chamber providing rapid initial flame growth and a secondary flow that assists in flame propagation. Moving-boundary simulations permit analysis of flame propagation in realistic engine configurations, and assessments of resulting combustion times.
\end{abstract}

\section{Nomenclature}

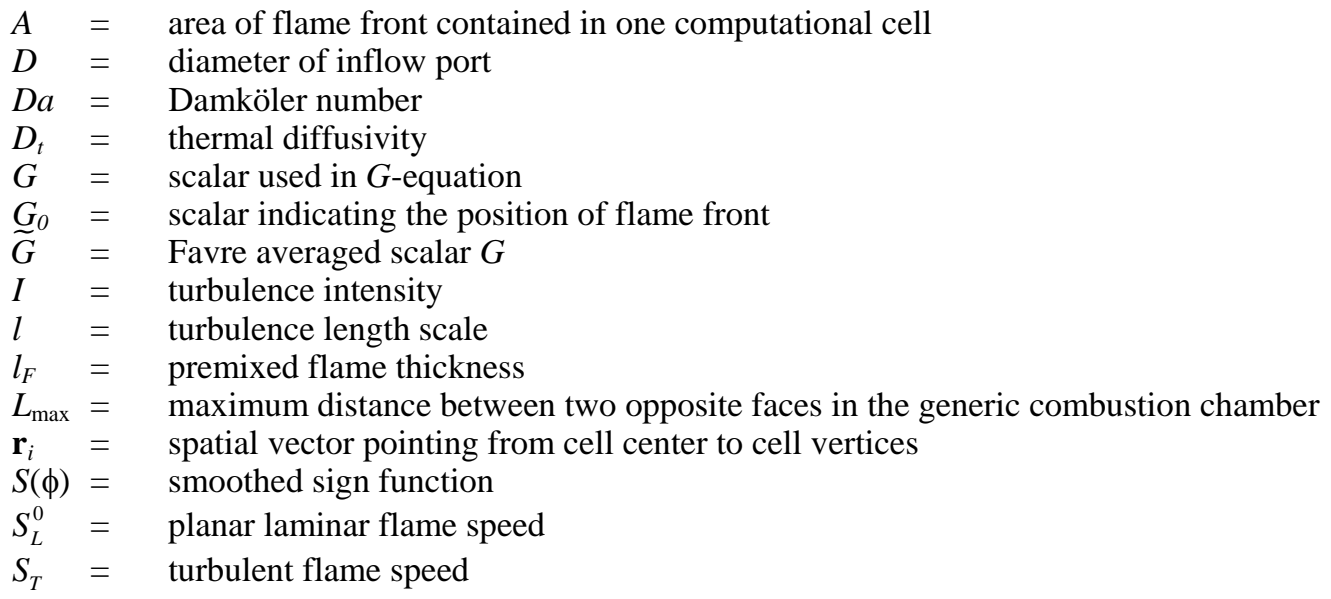

\footnotetext{
* Graduate student research assistant, Aerospace Engineering, University of Michigan, AIAA student member.

${ }^{\dagger}$ Professor \& Head, Laboratory for Turbulence and Combustion (LTC), Department of Aerospace Engineering. Fellow AIAA.
} 


$\begin{array}{lll}K & =\text { mean flow kinetic energy } \\ k & = & \text { turbulent kinetic energy } \\ V_{i} & = & \text { vertices of a computational cell } \\ V & = & \text { volume of a computational cell } \\ x_{b} & = & \text { burned mass fraction } \\ \phi & = & \text { variable used in reintialization of } G \text { field } \\ \tilde{\kappa} & = & \text { Favre averaged curvature } \\ \bar{\rho} & = & \text { average density in a computational cell } \\ \rho_{u} & = & \text { density of unburned gas } \\ \tau_{B} & = & \text { combustion time }\end{array}$

\section{Introduction}

COMBUSTION in microscale and mesoscale devices has become of rapidly-growing importance for a wide

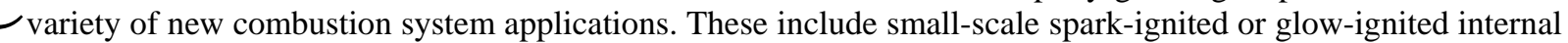
combustion (IC) engines with integrated electrical generators for portable power generation. In principle, such engines can achieve energy and power densities, on both mass and volume bases, far exceeding battery capabilities. However these engines still operate as Otto-cycle devices, and thus minimizing the combustion time to provide high peak pressure is the key to achieving high power and efficiency characteristics. In large-scale engines, combustion times are typically reduced by creating in-cylinder mean flow and turbulence characteristics that enhance flame propagation over the combustion chamber volume. However as Fig. 1 indicates, small-scale engines operate in a very different regime, in which it can be far more difficult to achieve turbulence-augmented minimization of the combustion time.

True microscale engines ${ }^{1-6}$ have submillimeter combustion chamber dimensions and chamber volumes of $\mathrm{O}\left(10^{-9}\right)$ $\mathrm{m}^{3}$. At such scales, typical injection pressures allow little or no in-chamber flow to be sustained, and the combustion time is thus determined largely by the maximum chamber dimension $L_{\max }$ and the nominal laminar flame speed $S_{L}^{0}$. By contrast, mesoscale engines ${ }^{7-9}$ such as that shown in Fig. 2 have characteristic dimensions typically of an order of magnitude larger, with combustion chamber volumes of $\mathrm{O}\left(10^{-6}\right) \mathrm{m}^{3}$. At these scales, significant in-chamber flow can be created by the injection process, and flame propagation over the combustion chamber volume can thus be significantly enhanced by the resulting mean flow and turbulence intensity fields. Properly tailoring these fields to the combustion chamber geometry allows significant reduction in the combustion time in mesoscale IC engines and thereby permits significant performance increases.

Guidelines for locating injection and ignition sites to give minimum combustion times in traditional macroscale engines are, however, of limited relevance for such mesoscale engines. Mesoscale combustion chamber shapes are often noncylindrical and can depend on the type of engine ${ }^{7-9}$. Moreover, in large-scale engines the turbulence kinetic energy $k=1 / 2 \overline{u_{i}^{\prime} u_{i}^{\prime}}$ can be sufficiently high for flame propagation to be in the fully-turbulent regime, and the mean flow kinetic energy $K=1 / 2 \bar{u}_{i} \bar{u}_{i}$ can

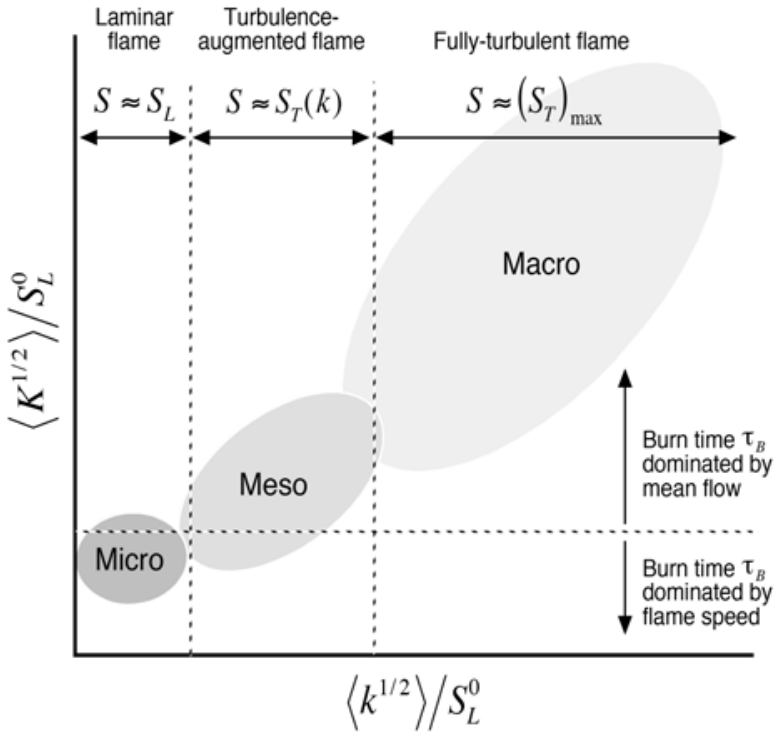

Figure 1. Combustion regimes for microscale, mesoscale, and macroscale combustion systems, determined by ratio of turbulence intensity $k$ to laminar flame speed $S_{L}^{0}$ and ratio of mean flow kinetic energy $K$ to laminar flame speed. be sufficiently high to provide rapid growth in flame surface area by the mean velocity field. By contrast, in mesoscale engines both $k$ and $K$ can be far smaller and flame propagation thus typically occurs in a very different regime.

\section{A. Flame Propagation in a Generic Mesoscale Combustion Chamber}

This study first examines premixed flame propagation in a generic mesoscale combustion chamber for various injection and ignition configurations, and identifies broadly applicable guidelines for minimizing the combustion time 
$\tau_{\boldsymbol{B}}$ in mesoscale engines. Numerical simulations based on the $G$-equation, together with mean flow and turbulence fields for various injection configurations, are used to identify key features of the premixed flame propagation and the resulting combustion times for generic combinations of injection and ignition sites. Characteristics of the flow that lead to effective means for augmenting flame propagation are identified, and general guidelines for achieving the minimum combustion times in mesoscale combustion chambers are established. The combustion time $\tau_{B}$ denotes the time during which $5 \% \sim 95 \%$ of the total reactant mass was consumed.

A generic combustion chamber was first used for this study that allows key issues applicable to a wide range of practical mesoscale combustion systems to be addressed. The geometry consisted of a rectangular parallelepiped with unequal lengths along the three axes, as shown in Fig. 3(left), having physical dimensions of $5 \mathrm{~mm} \times 8 \mathrm{~mm} \times 10 \mathrm{~mm}$. Here $L_{\max }=10 \mathrm{~mm}$ denotes the characteristic maximum dimension of the combustion chamber. A single round injection port with diameter $D=1 \mathrm{~mm}$ introduced a homogeneous stoichiometric methane/air mixture into the chamber at a constant mass flow rate. Four injection locations were studied on each of the three faces, giving the twelve configurations shown in Fig. 3(left). On each face, the ports were located at the center, on the two symmetry lines and in the corner centered $1 \mathrm{~mm}$ from the nearest edge. The geometry and injection configurations suffice to identify key aspects of the mean flow and turbulence fields in such mesoscale combustion chambers.
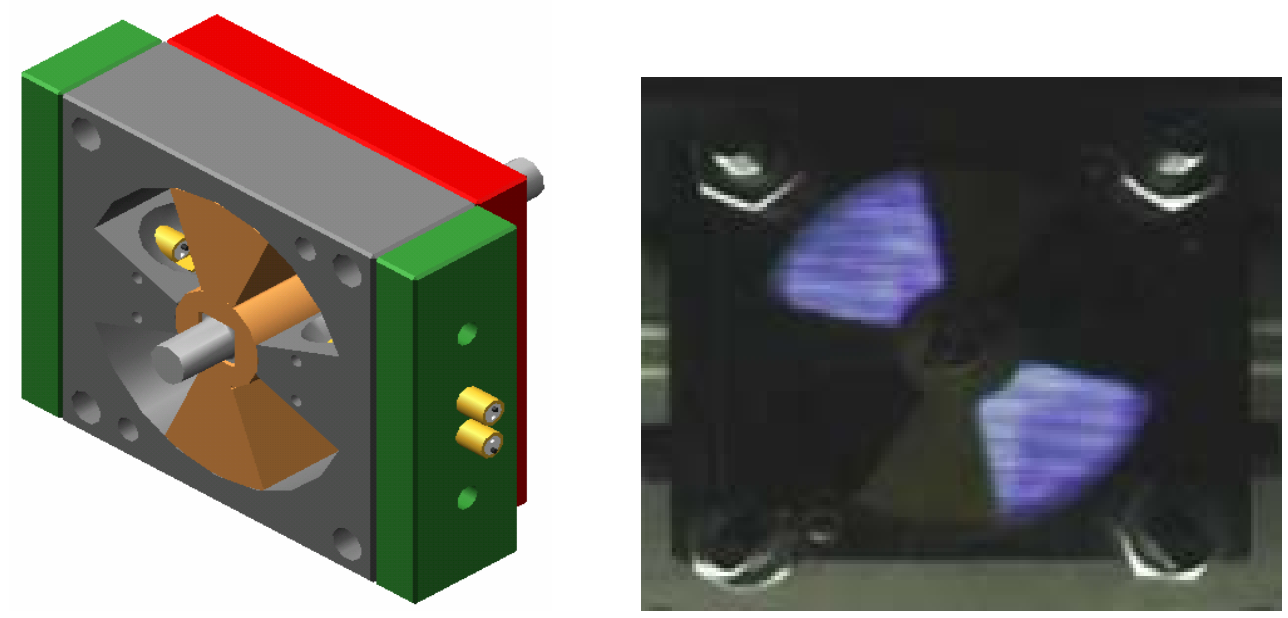

Figure 2. Example of mesoscale internal combustion swing engine (MICSE) ${ }^{8}$, showing non-cylindrical combustion chambers (left) and combustion visualization (right) revealing in-chamber turbulent flow and turbulence-enhanced flame propagation. Measured combustion time $\tau_{\boldsymbol{B}}$ values indicate significant mean flow and turbulence augmentation of flame propagation.
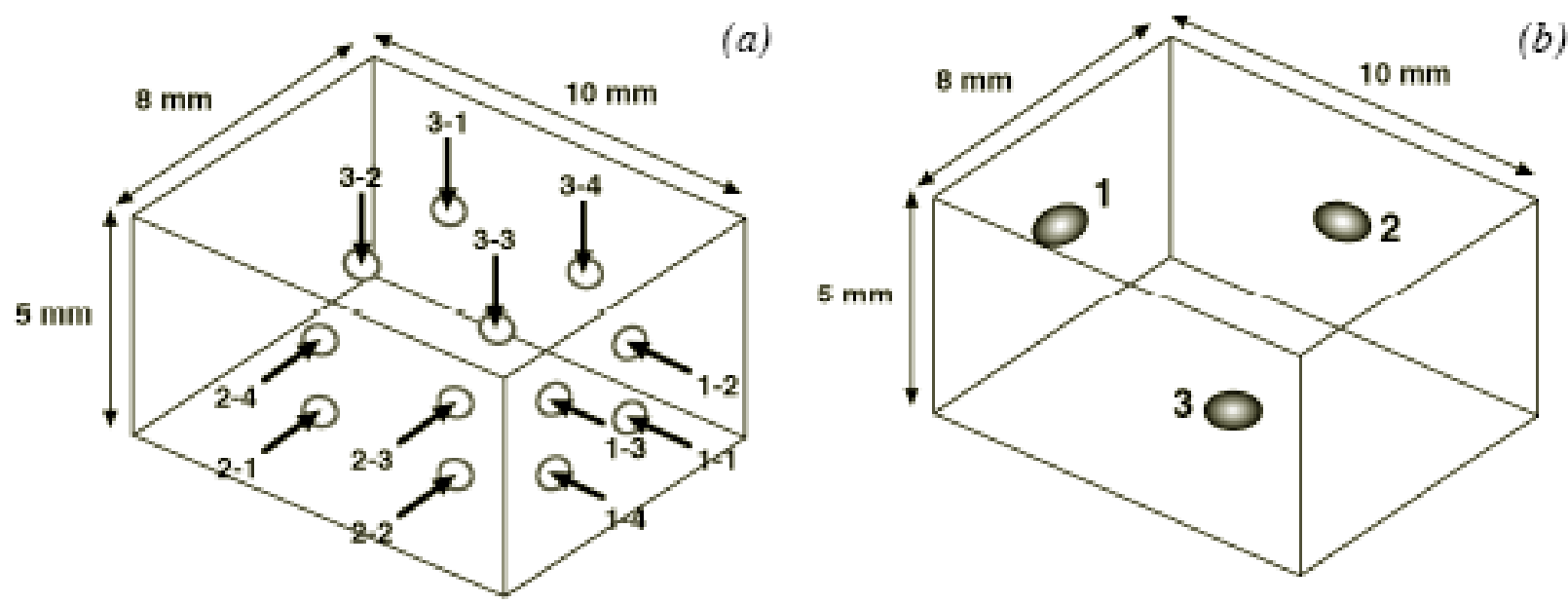

Figure 3. Generic mesoscale combustion chamber geometry in present study, showing injection locations (a) and ignition locations (b). 
In addition, three different ignition locations were examined, as shown in Fig. 3(right), centered on the three faces opposite to the injection ports. A single ignition location was used for each simulation. Most cases considered ignition directly opposite the face from which injection occurred, however several cases also considered the effect of varying the ignition location. The choice of injection port determines the mean flow and turbulence fields in the chamber, and the ignition location then determines the resulting flame propagation characteristics and combustion time. Simulation results for various combinations of injection and ignition locations allowed broadly applicable guidelines to be identified for minimizing the combustion time in such mesoscale devices.

\section{B. Flame Propagation in Mesoscale Internal Combustion Swing Engine Chamber}

The flame propagation in a mesoscale internal combustion swing engine chamber was further studied. The swing engine combustion chamber differs from the generic chamber shown in Fig. 3 with the movement of the swing arm during the flame propagation process. Two geometries of the combustion chamber for the swing engines are shown in Fig. 4 with the difference in the intake tube direction. The moving boundary, intake and exhaust ports are also colored in the figure. Modeling the flame propagation across such a combustion chamber requires including the moving boundary in the simulation. From a computational perspective, such moving boundaries significantly complicate the simulation. However the dynamic mesh capabilities in FLUENT can be used to model flows where the shape of the domain is changing with time due to motion of the domain boundaries. The boundary motion is here prescribed to be independent of the combustion progress within the chamber. The update of the volume mesh is handled automatically by FLUENT at each time step, based on the new positions of the boundaries. The top view of the dynamic mesh used in the simulations is shown in Fig. 5. The dynamic mesh model requires a starting volume mesh and the description of the motion of any moving zones in the model. The velocity or angular velocity of the moving boundary can be used to describe boundary motion. The swing arm angular velocity is roughly sinusoidal and at a typical swing frequency

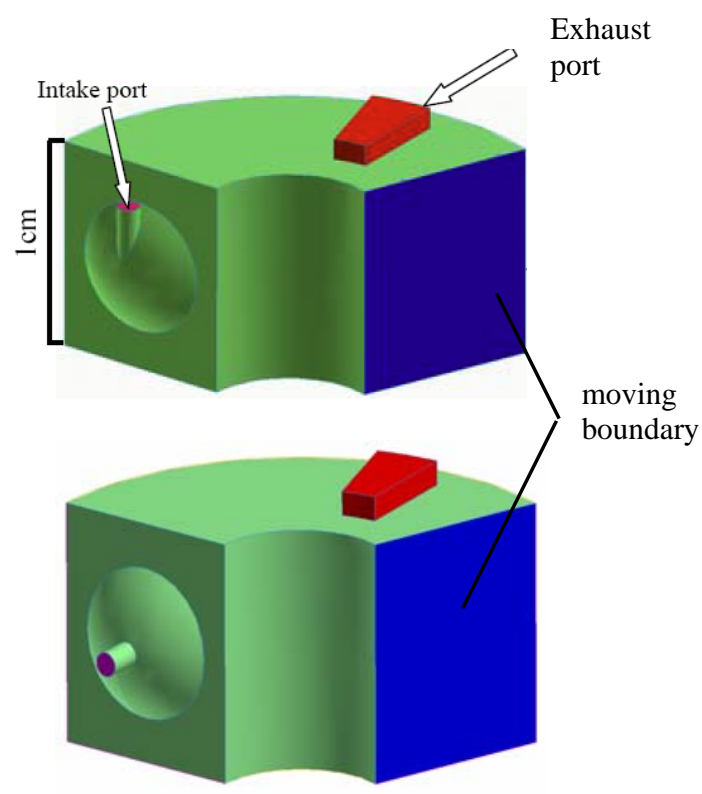

Figure 4. Schematic of moving boundary computational domain in one combustion chamber for actual swing engine geometry for side injection (top) and normal injection (bottom). around $100 \mathrm{~Hz}$. Thus in the present simulations, the position of the moving swing arm boundary is explicitly specified as

$$
\theta(t)=\frac{\pi}{4}[1-\cos (2 \pi f t)]
$$

where $f$ is the $100 \mathrm{~Hz}$ cycle frequency. The above equation prescribes the swing amplitude as $45^{\circ}$, with the resulting maximum and minimum angles of the combustion chamber being $110^{\circ}$ and $20^{\circ}$, respectively. Fig. 5 shows the mesh of the initial computational domain. The top views of the dynamics meshes generated based on the moving boundary described by are shown in Fig 6.

\section{Numerical Methods}

In spark ignition engine modeling, the burnt and unburnt gases are usually assumed to be separated by a relatively thin flame front where the chemical reactions take place. The flame can therefore be viewed as an ensemble of thin reactive-diffusive layers, called flamelets, which are embedded within a non-

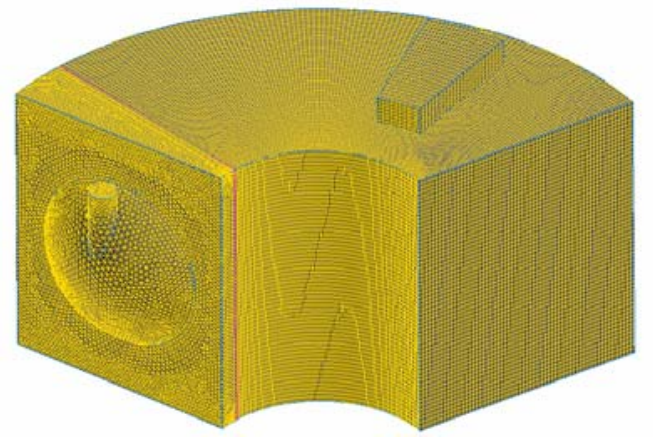

Figure 5. Coarse grid for side injection geometry in Fig. 4(top). 

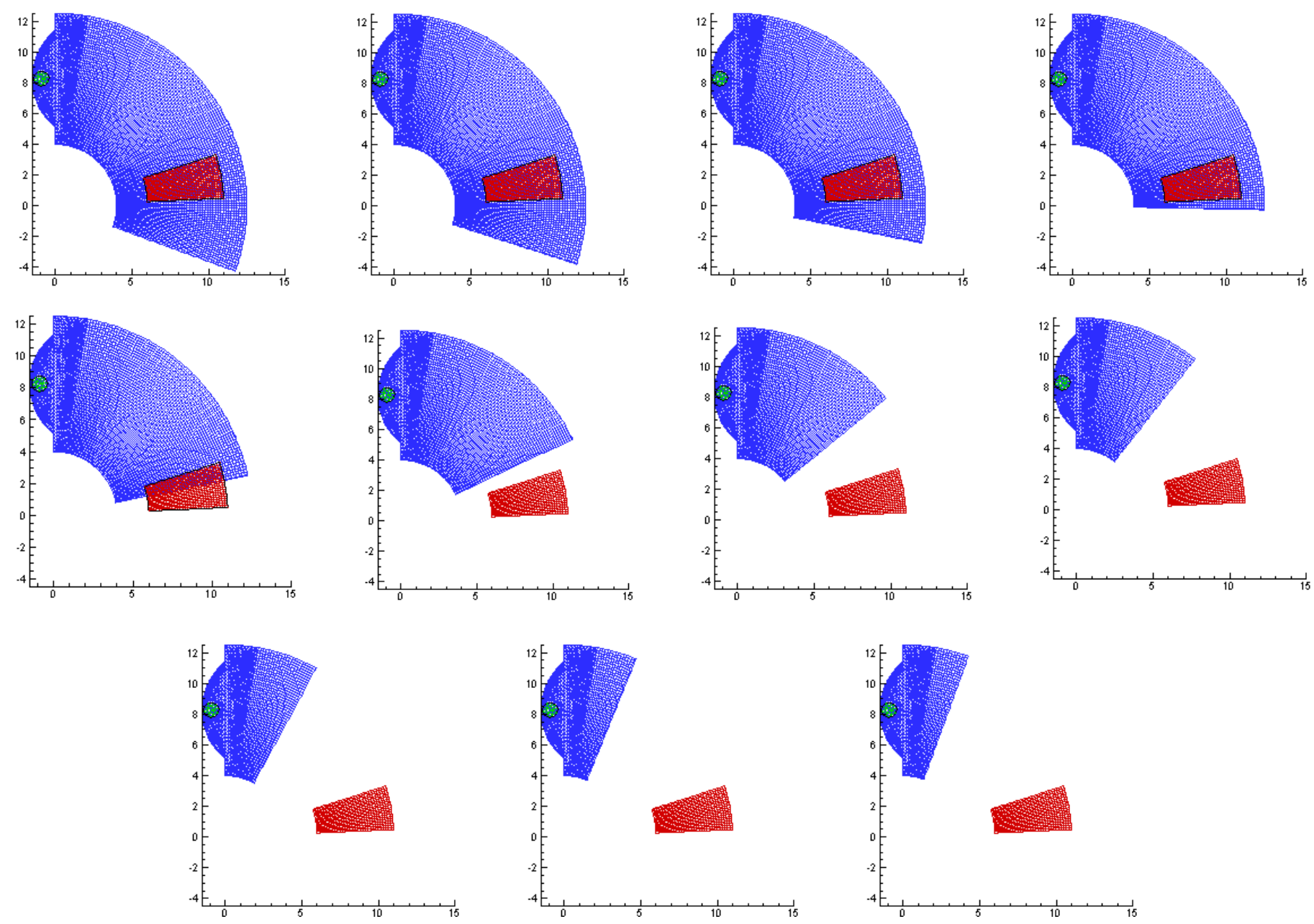

Figure 6. Top view of moving boundary computational domain, showing separate meshes for combustion chamber (blue) and exhaust port (red), (shown every $0.2 \mathrm{~ms}$; length in $\mathrm{mm}$ ). 
reacting turbulent flow ${ }^{10}$. Based on the flamelet concept, various models have been proposed to simulate turbulent premixed combustion. Among these models, the Bray-Moss-Libby model ${ }^{11}$, the coherent flame model ${ }^{12}$ and the levelset (G-equation) model ${ }^{13}$ are widely used in numerical simulations of turbulent combustion.

Recently, the levelset ( $G$-equation) modeling has received more attention. In this model, the mean flame front is represented by an iso-surface of scalar $G$ field. Since the scalar $G$ is a nonreacting variable, there is no need for a chemical source closure term. Through turbulent combustion modeling, the transport equation for the mean $G$ was formulated ${ }^{13}$. By solving the mean $G$-equation, the flame front in turbulent combustion can therefore be tracked.

In solving turbulent combustion problem using $G$-equation, the flow field is usually simulated using commercial CFD software such as FIRE $^{14}$ and $\mathrm{KIVA}^{15}$. In the current study, FLUENT is used together with user developed Gequation solver to simulate flame propagation in mesoscale combustion chambers.

\section{Premixed Flame Propagation}

In spark ignition engines, combustion usually falls into the following three types of regimes, namely, wrinkled flamelet, corrugated flamelet and thin reaction $z \mathrm{zen}^{16}$, where the flame inner layer is not perturbed by the turbulent eddies. In order to track flame front, a levelset approach was introduced by Williams ${ }^{10}$. The flame front is defined by $G(\mathbf{x}, t)=0$. This interface divides the flow field into unburnt region, $G<0$, and a burnt gas region, $G>0$. The Favreaveraged $G$ transport equation can be written as ${ }^{13}$

$$
\frac{\partial \bar{\rho} \widetilde{G}}{\partial t}+\nabla \cdot(\bar{\rho} \tilde{\mathbf{v}} \widetilde{G})=\rho_{u} s_{T}|\nabla \widetilde{G}|-\bar{\rho} D_{t} \tilde{\kappa}|\nabla \widetilde{G}|
$$

where $\bar{\rho}_{u}$ is the unburned gas density and $\bar{\rho}$ is the gas density at the mean location of the turbulent flame, $S_{T}$ is the turbulent flame speed, which depends on local laminar flame speed and flow condition, $\tilde{\kappa}$ is the mean flame front curvature and can be expressed in terms of the levelset function $\tilde{G}$ as

$$
\tilde{\kappa}=\nabla \cdot\left(-\frac{\nabla G}{|\nabla G|}\right)
$$

Suitable numerical schemes have been developed to evaluate $G$ gradient in the $G$-equation ${ }^{17,18}$. In the current study, a method based on least-square fitting is used to calculate the $G$ gradient on an unstructured grid ${ }^{19}$. The convection term will be solved using QUICK scheme in FLUENT.

\section{Reinitialization}

In modeling turbulent combustion, it is almost not possible to maintain the levelset function as a signed distance from the moving $G_{0}$ surface, because of the turbulent nature of the advecting flow field. Flat or steep regions develop as the interface moves, rendering computation at these places inaccurate. It is therefore necessary to introduce a procedure that will reset the $G$-field to the signed distance from $G_{0}$ in a predefined neighborhood of $G_{0}$. In order to reset the $G$ field to the signed distance from the $G_{0}$ surface, the following equation is solved to a steady state ${ }^{20}$.

$$
\begin{gathered}
\frac{\partial \phi}{\partial t}=S\left(\phi_{0}\right)(1-|\nabla \phi|) \\
\phi_{0}=G(\mathbf{x}, 0)
\end{gathered}
$$

where $S\left(\phi_{0}\right)$ is a smoothed sign function defined as

$$
S(\phi)=\frac{\phi}{\sqrt{\phi^{2}+|\nabla G|^{2}(\Delta x)^{2}}}
$$

where $\Delta \mathrm{x}$ is the characteristic length scale of grid. 


\section{E. Flame Front Reconstruction in Computational Cell}

In the present $G$-equation simulations, the source terms in the energy and species transport equations require evaluation of the flame surface area contained within each computational cell. The procedure used here to calculate the flame front in any given cell involves the following steps as illustrated in Fig. 7. First, the points $p_{i}$ at which the flame front intersects the cell edges, labeled $1-6$ in Fig. 7 must be found. By definition, $G\left(p_{\mathrm{i}}\right)=0$. To locate these points, the $G$ values at the cell vertices must be calculated. Since $G$ and $\nabla G$ at the cell center are known, the values at the cell vertices are approximated based on the extrapolation

$$
G\left(V_{i}\right)=G_{c}+\nabla G_{c} \cdot \mathbf{r}_{i}
$$

where $G\left(V_{i}\right)$ represents the $G$ value at vertex $V_{i}, G_{c}$ and $\nabla G_{c}$ are values at the center of the cell, and $\mathbf{r}_{\mathrm{i}}$ is the spatial vector pointing from cell center to vertex $V_{i}$. Once the $G$ value at each cell vertex is known, linear interpolation is used to determine the positions of zero $G$ points $p_{i}$, namely $G\left(p_{i}\right)=0$. Next, the area of the flame surface contained within the cell must be calculated. In general, the shape of the flame front within the cell could be arbitrary, however here the flame front in the cell is defined by the complex surface formed from the combination of the four triangles defined by the points $p_{i}$ as 123, 134, 145 and 156 in Fig. 7. The area is then the sum of the areas of all of these triangles. To avoid constructing triangles with overlapping area, an essential step is to order the points $p_{i}$ properly in the three-dimensional cell space.

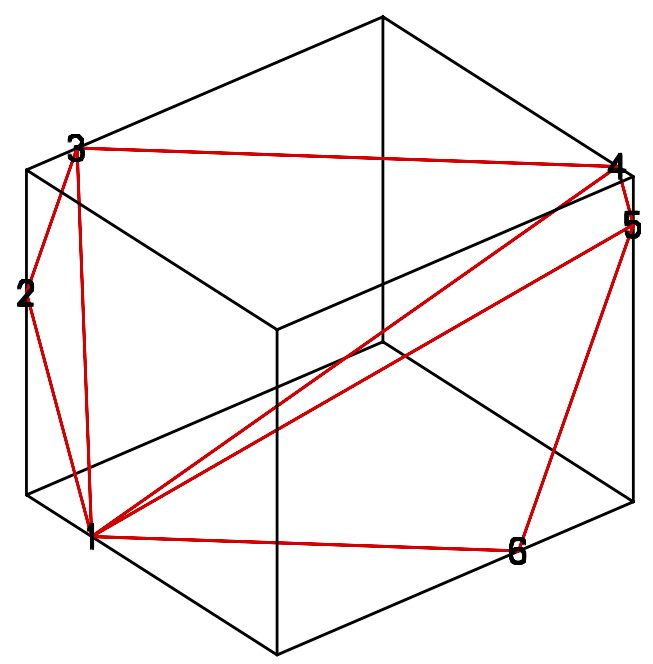

Figure 7. Schematic showing geometry for flame front reconstruction in a cell. Points numbered 1-6 are flame surface $(G=0)$ points at cell edges. Flame front area within cell is the sum of all subtriangles.

\section{F. Turbulent and Laminar Flame Speed}

The turbulent burning velocity in Eq. (2) is evaluated using ${ }^{21}$

$$
s_{T}=s_{L}^{0}+v^{\prime}\left\{-\frac{a_{4} b_{3}^{2}}{2 b_{1}} D a+\left[\left(\frac{a_{4} b_{3}^{2}}{2 b_{1}} D a\right)^{2}+a_{4} b_{3}^{2} D a\right]^{1 / 2}\right\}
$$

where $\mathrm{v}^{\prime}$ is the turbulence intensity, and $a_{4}=0.78, b_{1}=2.0$ and $b_{3}=1.0$ are constants derived from the turbulence model, and

$$
D a=s_{L}^{0} / v^{\prime} l_{F}
$$

where $l$ is the turbulence integral length scale, and $l_{F}$ is the flame thickness defined as

$$
l_{F}=\left(\lambda / c_{p}\right)_{0} /\left(\rho s_{L}^{0}\right)_{u}
$$

where heat conductivity, $\lambda$, and heat capacity $c_{p}$, are evaluated at the inner layer temperature. The laminar burning velocity $S_{L}^{0}$, and the density are evaluated in the unburned gas.

The laminar burning velocity $S_{L}^{0}$ was calculated using PREMIX ${ }^{22}$ subroutine in the CHEMKIN library based on detailed chemical kinetics and mixture transport properties. By using GRIMech 2.11 kinetics $^{23}$, the laminar burning velocities of premixed stoichimetric methane-air flames at adiabatic conditions were obtained. The resulting laminar premixed burning velocities for various reactant temperatures and pressures are shown in Fig. 8. It can be seen that with increasing pressure and decreasing reactant temperature, the laminar burning velocity decreases. From the pressure- and temperature-dependent laminar burning velocities obtained in this manner over the range from $1 \mathrm{~atm} \leq p$ 
$\leq 12 \mathrm{~atm}$ and $300 \leq T \leq 1100 \mathrm{~K}$, linear interpolation is used to obtain the laminar premixed burning velocity at any other temperature and pressure within these ranges.

\section{G. Mean Flow and Turbulence}

A standard fluid dynamics code (FLUENT) was used to determine the mean velocity field $\overline{\mathbf{u}}_{i}(\mathbf{x})$ and turbulent kinetic energy field $k(\mathbf{x})=1 / 2 \overline{u_{i}^{\prime} u_{i}^{\prime}}(\mathbf{x})$ for each configuration. The standard Favre-averaged $\tilde{k}-\tilde{\varepsilon}$ model was used for the turbulence. The turbulence intensity $I$, and length scale $l$ are specified at the inlet. Therefore, the turbulent kinetic energy $k$, and turbulent kinetic energy dissipation rate $\varepsilon$ were calculated as $k=3(\overline{u I})^{2} / 2 \quad$ and $\varepsilon=C_{\mu}^{3 / 4} k^{3 / 2} / l$. The turbulent length scale is assumed to be $0.07 D$, where $D$ is diameter of the inlet port. Since the Reynolds number in the mesoscale combustion chamber is relatively small, special treatment for the turbulence near the wall is required. Here the two-layer model for near-wall turbulence together with finer mesh near the wall is used. Grid convergence was verified on unstructured hexahedral grids, with essentially identical results obtained on the coarse and fine grids. And the temporal converges was also verified on two time steps 0.025 and 0.05 milliseconds. To allow direct comparisons between configurations, the same injector diameter and flow rate were used for each case.

Although limitations of the standard Favre-averaged $k-\varepsilon$ model for representing turbulent transport are known, the identical turbulence model with standard values was used for all cases to allow direct comparisons between various injection and ignition configurations. Moreover, the high confinement in such mesoscale combustion chambers results in the flow being more strongly dictated by the geometry than in macroscale systems, and thus is influenced comparatively less by the turbulence model.

For cells containing pieces of flame front, the energy equation includes an extra source term, $S_{h}$, due to heat release of combustion as

$$
S_{h}=\rho Q \frac{S_{T} A}{V}
$$

where $\rho$ is the density, $Q$ is heat of reaction, $A$ is the area of flame front contained in the computational cell, $S_{T}$ is turbulent flame speed and $V$ is the volume of the cell.

\section{H. Reinitialization Test}

A test case of the reinitialization process allows an assessment of the procedure. The initial $G$ field is taken as

$$
G(x, y)=f(x, y)\left(\sqrt{\frac{x^{2}}{4^{2}}+\frac{y^{2}}{2^{2}}}-1\right)
$$

where

$$
f(x, y)=0.1\left[0.1+(x-3.5)^{2}+(y-2.0)^{2}\right]
$$


The $G_{0}$ surface described by Eq. (12) and (13) is an ellipse with horizontal and vertical axis of 4 and 2 units, respectively. The computational domain is taken as $x=[-5,5], y=[-5,5]$. Fig. 9 shows reinitialization of the distorted $G$ field, in which the ellipse defined by the bold contour line is the $G=0$ isosurface. Initially, $|\nabla G| \neq 1$, however the reinitialization can be seen to drive $|\nabla G| \rightarrow 1$ in the vicinity of $G=0$.

\section{Test Case of a Two-dimensional Slot Burner Flame}

In the present test case, the $G$-equation solver is used to simulate a laminar premixed flame stabilized at a twodimensional slot burner. Experimental visualizations ${ }^{24}$ are available for comparison of the flame shape and the flow field produced by such a burner for the case of a methane-air flame at equivalence ratio of 1.2. Fig. 10 (left) shows the flame geometry as visualized by the emission from excited radicals at the reaction zone, as well as corresponding flow streamlines visualized by the tracks of $1-5 \mu \mathrm{m}$ diameter $\mathrm{MgO}$ particles seeded into the flow and illuminated by a light
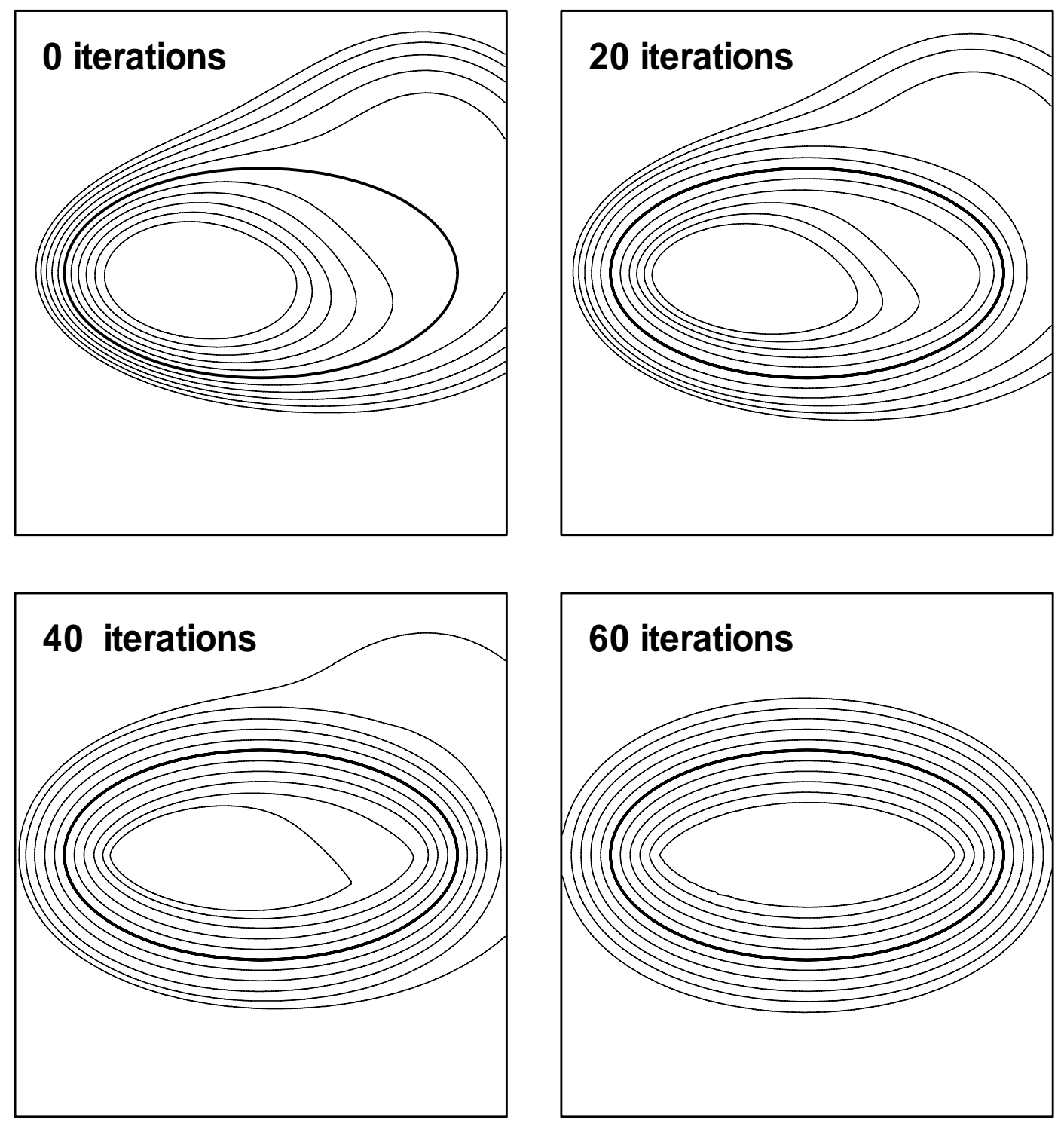

Figure 9. Reinitializtion test with initial $G$ distribution prescribed by Eq. (12) and(13). The computational domain is $10 \times 10$ and a $50 \times 50$ rectangular mesh is used. 
sheet from a $20 \mathrm{~W}$ copper vapor laser operating at a $6 \mathrm{kHz}$ pulse rate. The simulation is set up to reflect the geometry and operating conditions in the experiment. Thus the width of the slot burner at the exit is $6.8 \mathrm{~mm}$, and the flow condition at the inlet boundary is a uniform velocity of $1.5 \mathrm{~m} / \mathrm{s}$. The laminar burning velocity of a premixed methaneair flame with equivalence ratio of 1.2 is about $0.4 \mathrm{~m} / \mathrm{s}$. In the current simulation, the computational domain is $3 d \times$ $3 d$, where $d$ is the width of the slot exit, and the computations are performed on a $180 \times 180$ rectangular grid.

The simulation results in Fig. 10 (right) give the flame surface shape as well as the computed streamlines for comparison with the experimental results. It can be seen from the comparison that the present simulation approach correctly determines the flame front and streamline pattern. The key differences are in the slightly different height of the computed flame surface, and the slightly curved shaped seen at the sides of the flame in the experimental results. These differences result from the assumed uniform inlet boundary condition. In the experiment, the mean inlet velocity is given as $1.5 \mathrm{~m} / \mathrm{s}$, however the actual inlet flow velocity profile is not given, but will not be strictly uniform due to boundary layer at the walls of the slot burner. Thus, although the average velocity is $1.5 \mathrm{~m} / \mathrm{s}$, the maximum velocity at the center of the channel must be greater that this value, which makes the flame longer. The reduced unburned gas velocity at the inflow boundary of burner also leads to the slight curvature at the sides of the flame in the experimental results. Since the details of the inflow velocity profile in the experiments are not known, in the present simulations the inflow velocity profile was taken to be uniform. Nevertheless, the comparison in Fig. 6 serves to demonstrate that the present G-equation solver methodology and its coupling to the FLUENT solver for the flow field can provide accurate results for premixed flame propagation.

\section{Results and Discussions}

By solving $G$-equation together with flow equations, the flame propagation in a generic mesoscale combustion chamber was simulated. The combustion times $\tau_{B}$ for all thirty six cases are given in Table 1 . Note that $\tau_{B}$ for Case $3-2$
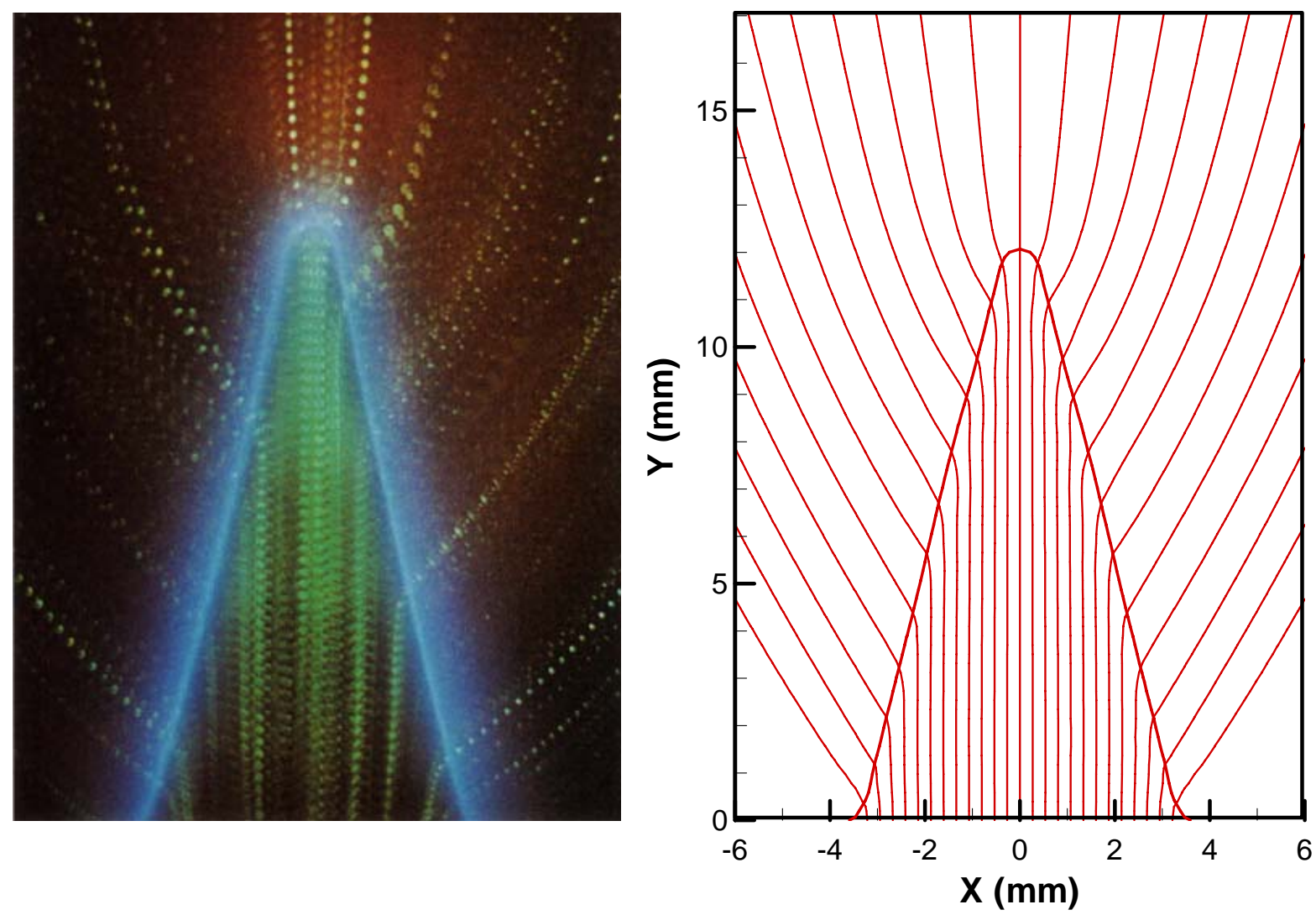

Figure 10. Validation tests showing comparison between measured (left) and present computed (right) flame for a laminar premixed methane/air $(\phi=1.2)$ flame stabilized on a 2-D slot burner. (Photograph from Echekki \& Mungal, 1990.) 
(1), the fastest-burning configuration, is only about $40 \%$ that Case 2-4 (3), the slowest-burning configuration. Engine modeling based on a Wiebe-function with specified $\tau_{B}$ shows a substantial effect of such a reduction in combustion time on the engine efficiency and power output. For example, reducing $\tau_{B}$ from $1.0 \mathrm{~ms}$ to $0.5 \mathrm{~ms}$ in the mesoscale engine in Fig. 2 leads to a 58\% increase in thermal efficiency and a $39 \%$ increase in power ${ }^{8}$. Minimizing $\tau_{B}$ by properly tailoring the mean flow and turbulence produced by injection into the combustion chamber geometry is thus essential to developing effective mesoscale IC engines.

Table 1 also shows the scaling of $\tau_{B}$ relative to characteristic laminar flame, turbulent flame and mean flow time that may be used to estimate the combustion time in any given configuration. Note in particular that, for mesoscale combustion $\tau_{B}$ can be 8-20 times faster than the nominal laminar flame time scale $L_{\max } / S_{L}^{0}$ that governs true microscale combustion. Moreover, the $\tau_{B}$ values in Table 1 are about 0.5-1.3 the nominal turbulent flame time scale $L_{\max } / S_{T}^{0}$, and are round 0.4-0.9 the nominal mean flow time scale $L_{\max } / K^{1 / 2}$. The latter indicates that the turbulence and mean flow both have significant and roughly comparable effects on the augmentation of flame propagation in such mesoscale devices.

\section{A. Effects of Ignition Location for Generic Combustion Chamber}

The ignition locations determine the places of the onset of flame propagation. Tables 1 also shows that ignition location (3) and (1) always give, respectively, the shortest and the longest burn times, with the combustion time for ignition location (2) always giving the intermediate value for the combustion time. The order of the combustion times based on ignition locations from can be explained as follows. As flame propagates across the chamber, it starts from the wall and the burn time is determined by the longest distance from the ignition kernel to each of the walls. For ignition locations (1), (2) and (3), this longest distance is 10 $\mathrm{mm}, 8 \mathrm{~mm}$ and $5 \mathrm{~mm}$, respectively. Since ignition location (3) has the shortest distance for flame to travel, it always has the shortest combustion time.

The determination of longest travel distance on combustion time can also be seen from the burned mass fraction $x_{b}$ profiles for opposite injection and ignition configurations (Fig. 11). Fig. 11 show the burned mass fraction profiles vs. scaled time for three opposite injection and ignition pairs, respectively. Despite small difference made by different injection locations on the same injection faces, the ignition locations (3) and (1) give the shortest and longest time, respectively, and ignition location (2) gives the intermediate combustion time. It can also be seen that the burned mass fraction profiles generally have the shape of Wiebe's function ${ }^{8}$. At the early and late stage of flame propagation, the burn mass fraction increases slowly due to the small area of flame surface at these stages. However, burned mass fraction increases rapidly in the intermediate
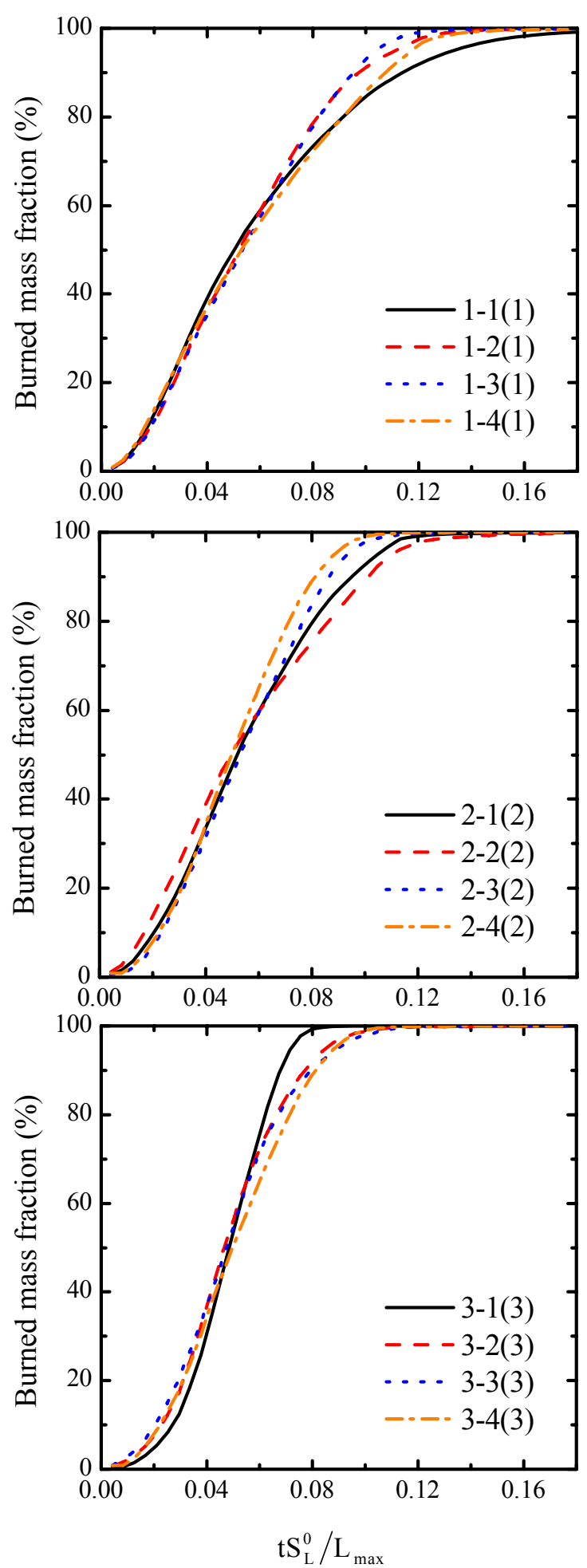

Figure 11. Burned mass fraction vs. scaled time for opposite ignition/injection configurations. 
Table 1. Combustion time $\tau_{\mathrm{B}}$ for all configurations and scaling of $\tau_{\mathrm{B}}$ with $L_{\max } / S_{L}^{0}, L_{\max } / S_{T}^{0}(k), L_{\max } / K^{1 / 2}$.

\begin{tabular}{|c|c|c|c|c|c|c|c|c|c|}
\hline Case & $\tau_{B}(\mathrm{~ms})$ & $\frac{\tau_{b} S_{L}^{0}}{L_{\max }}$ & $\frac{\tau_{B} S_{T}^{0}(k)}{L_{\max }}$ & $\frac{\tau_{B} K^{1 / 2}}{L_{\max }}$ & Case & $\tau_{B}(\mathrm{~ms})$ & $\frac{\tau_{b} S_{L}^{0}}{L_{\max }}$ & $\frac{\tau_{B} S_{T}^{0}(k)}{L_{\max }}$ & $\frac{\tau_{B} K^{1 / 2}}{L_{\max }}$ \\
\hline 1-1(1) & 2.9 & 0.122 & 1.319 & 0.783 & $2-3(1)$ & 2.21 & 0.093 & 0.947 & 0.794 \\
\hline $1-1(2)$ & 2.2 & 0.092 & 1.000 & 0.594 & $2-3(2)$ & 1.81 & 0.076 & 0.775 & 0.650 \\
\hline 1-1(3) & 1.6 & 0.067 & 0.728 & 0.432 & $2-3(3)$ & 1.33 & 0.056 & 0.570 & 0.478 \\
\hline $1-2(1)$ & 2.4 & 0.101 & 1.067 & 0.769 & $2-4(1)$ & 2.25 & 0.095 & 1.070 & 0.918 \\
\hline $1-2(2)$ & 1.9 & 0.080 & 0.845 & 0.608 & $2-4(2)$ & 1.73 & 0.073 & 0.823 & 0.706 \\
\hline $1-2(3)$ & 1.4 & 0.059 & 0.622 & 0.448 & $2-4(3)$ & 1.21 & 0.051 & 0.575 & 0.494 \\
\hline $1-3(1)$ & 2.2 & 0.092 & 0.971 & 0.815 & $3-1(1)$ & 2.28 & 0.096 & 0.964 & 0.764 \\
\hline $1-3(2)$ & 1.77 & 0.074 & 0.781 & 0.656 & $3-1(2)$ & 1.9 & 0.080 & 0.803 & 0.637 \\
\hline $1-3(3)$ & 1.24 & 0.052 & 0.547 & 0.459 & $3-1(3)$ & 1.25 & 0.053 & 0.528 & 0.419 \\
\hline $1-4(1)$ & 2.54 & 0.107 & 1.160 & 0.770 & $3-2(1)$ & 3.08 & 0.129 & 1.160 & 0.733 \\
\hline $1-4(2)$ & 1.98 & 0.083 & 0.905 & 0.600 & $3-2(2)$ & 2.37 & 0.100 & 0.893 & 0.564 \\
\hline $1-4(3)$ & 1.37 & 0.058 & 0.626 & 0.415 & $3-2(3)$ & 1.65 & 0.069 & 0.621 & 0.392 \\
\hline $2-1(1)$ & 2.71 & 0.114 & 1.095 & 0.699 & $3-3(1)$ & 2.92 & 0.123 & 1.112 & 0.676 \\
\hline $2-1(2)$ & 2.15 & 0.090 & 0.868 & 0.555 & $3-3(2)$ & 2.13 & 0.089 & 0.811 & 0.493 \\
\hline $2-1(3)$ & 1.58 & 0.066 & 0.638 & 0.408 & $3-3(3)$ & 1.81 & 0.076 & 0.689 & 0.419 \\
\hline $2-2(1)$ & 2.68 & 0.113 & 1.172 & 0.701 & $3-4(1)$ & 2.43 & 0.102 & 1.030 & 0.868 \\
\hline $2-2(2)$ & 2.37 & 0.100 & 1.036 & 0.620 & $3-4(2)$ & 2.05 & 0.086 & 0.869 & 0.732 \\
\hline $2-2(3)$ & 2.69 & 0.113 & 1.176 & 0.703 & $3-4(3)$ & 1.2 & 0.050 & 0.509 & 0.429 \\
\hline
\end{tabular}




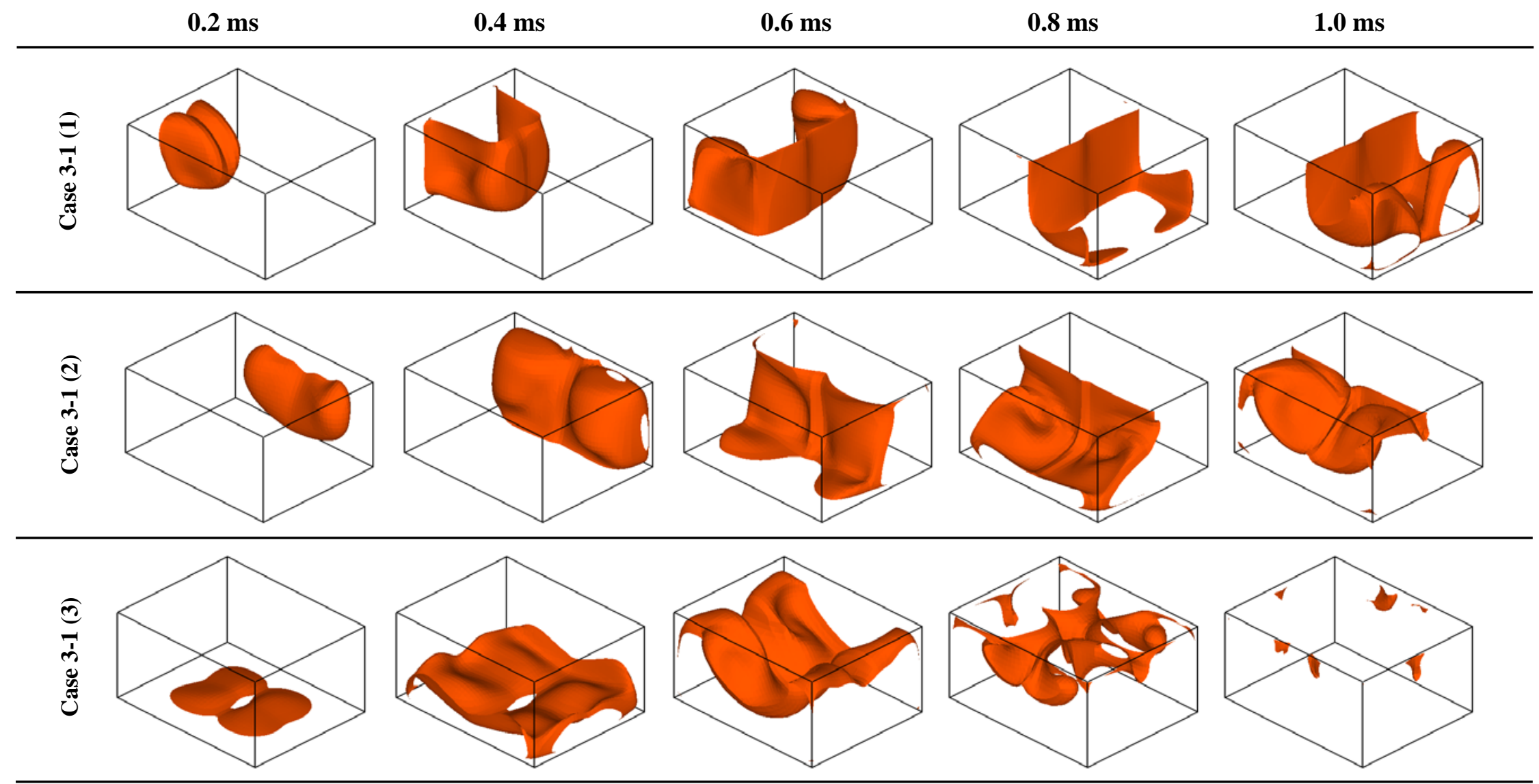

Figure 12. Flame surface vs. time for injection configuration 3-1 with ignition in opposite wall (bottom) and on two side walls (top and middle), revealing effect of ignition location on overall combustion time scale. 
stage due to the large area of flame surfaces. Small variations away from Wiebe's function in the shape of burned mass fraction profiles result from effects of mean flow fields.

The typical flame surface propagation scenarios are also show in Fig. 12 in which the injection location is fixed as 3-1 and ignition locations are subject to change. The flame surfaces of five times are shown in this figure. Although the initial flame kernel is spherical, after a short time, the flamesurfaces at $0.2 \mathrm{~ms}$ clearly show the strong effects of the convection of mean flow field. With the flame propagation, the area of flame surface increases which leads to rapid consumption of reactants and resulting large burned mass fraction increase. It is apparent from Fig. 12 that ignition on either of the two side walls results in flame propagation that is much slower than for opposite ignition, which is consistent with the observations above from Table 1.

\section{B. Effects of Injection Location for Generic Combustion Chamber}

Fig. 13 shows the simulated flame surface at five times after ignition for four representative configuration ranging from the fastest (Case 3-4(3)) to the slowest (Case 3-2(1)) combustion time $\tau_{\boldsymbol{B}}$. Note there are very significant differences in the pattern of flame propagation across the combustion chamber, which provide the basis for identifying configurations that serve to minimize the combustion time.

Close examination of the four cases in Fig. 13 reveals the major features that separate effective from ineffective injection configurations. The various injection locations can be seen from the flame shape to produce very different primary and secondary flow patterns in the combustion chamber. Primary flows result principally from impingement of the injection flow on the opposite wall, whereas secondary flows are typically associated with the effects of edges or corners and produce additional components of rotation beyond that implied by the primary flow. In general, secondary flows that serve to transport the flame rapidly across the chamber are most effective in reducing the combustion time.

It is apparent in the results in Fig. 13 that ignition opposite to the injection location, as in Case 3-4(3), allows the flame surface area to initially increase most rapidly due to the strain imposed by the primary flow. Moreover, the secondary flow pattern produced by injection helps to transport the resulting large flame surface across the chamber. In view of this, it is apparent that $\tau_{B}$ is then minimized when the secondary flow transports the flame across the shortest dimension of the chamber, as applies for Case 3-4(3).

\section{Flame Propagation in Swing Engine Chambers}

In this section, simulations of the flame front propagation in the combustion chamber are carried out using the levelset turbulent combustion modeling approach described in above. The simulation starts with the swing-arm at its right-most extremum position that corresponds to the maximum volume of the combustion chamber. The wall of the swing arm moves from right to left, and when it reaches its left-most extremum position, combustion is initiated by setting the flame kernel in the $G$ field as

$$
G\left(x, y, z, t_{0}\right)=0.0008-\sqrt{x^{2}+(y-0.00825)^{2}+(z-0.005)^{2}} .
$$

This assignment of the $G$ field produces in an initially spherical flame kernel with $0.8 \mathrm{~mm}$ radius and with its center at $(0,0.00825,0.005) \mathrm{mm}$. The initialization of the $G$ field at the left-most extremum of the swing arm motion provides spark ignition when the gas reaches its maximum compression, and thus corresponds to a zero spark advance timing.

For the baseline chamber geometry, the simulation was conducted with coarse and fine meshes. When the swing arm moves to its left-most extremum position, the combustion chamber has its minimum volume. At this moment, the flame is initiated by assigning initial $G$ field described by Eq. (14), so that the simulation corresponds to a case with no spark advance. The flame front propagation in the baseline combustion chamber is shown in Fig 14, where the first panel shows the spark ignition kernel. As the flame propagates, reaches the sidewalls first since the chamber geometry is still comparatively flat at this early time. With further propagation the flame surface becomes divided into several pieces close to the corners. It takes a relatively long time for these parts of the flame front to disappear, since at the corners of the chamber the turbulent kinetic energy is rather low and the resulting flame speed is thus close to the laminar burning velocity.

The burned mass fraction profiles for both the basic and side injection geometries are shown in Fig 15. There is only a minor difference in the burn time for these two injection schemes. Since the turbulent kinetic energy plays a crucial role in determining the burn time and the turbulent kinetic energy is affected by both the reactant inlet and the motion of the swing arm, it is useful to simulate flame propagation with the engine running at different frequencies. The flame propagation for engine frequencies of $50 \mathrm{~Hz}$ and $150 \mathrm{~Hz}$ were thus simulated as well. The mean turbulent kinetic 


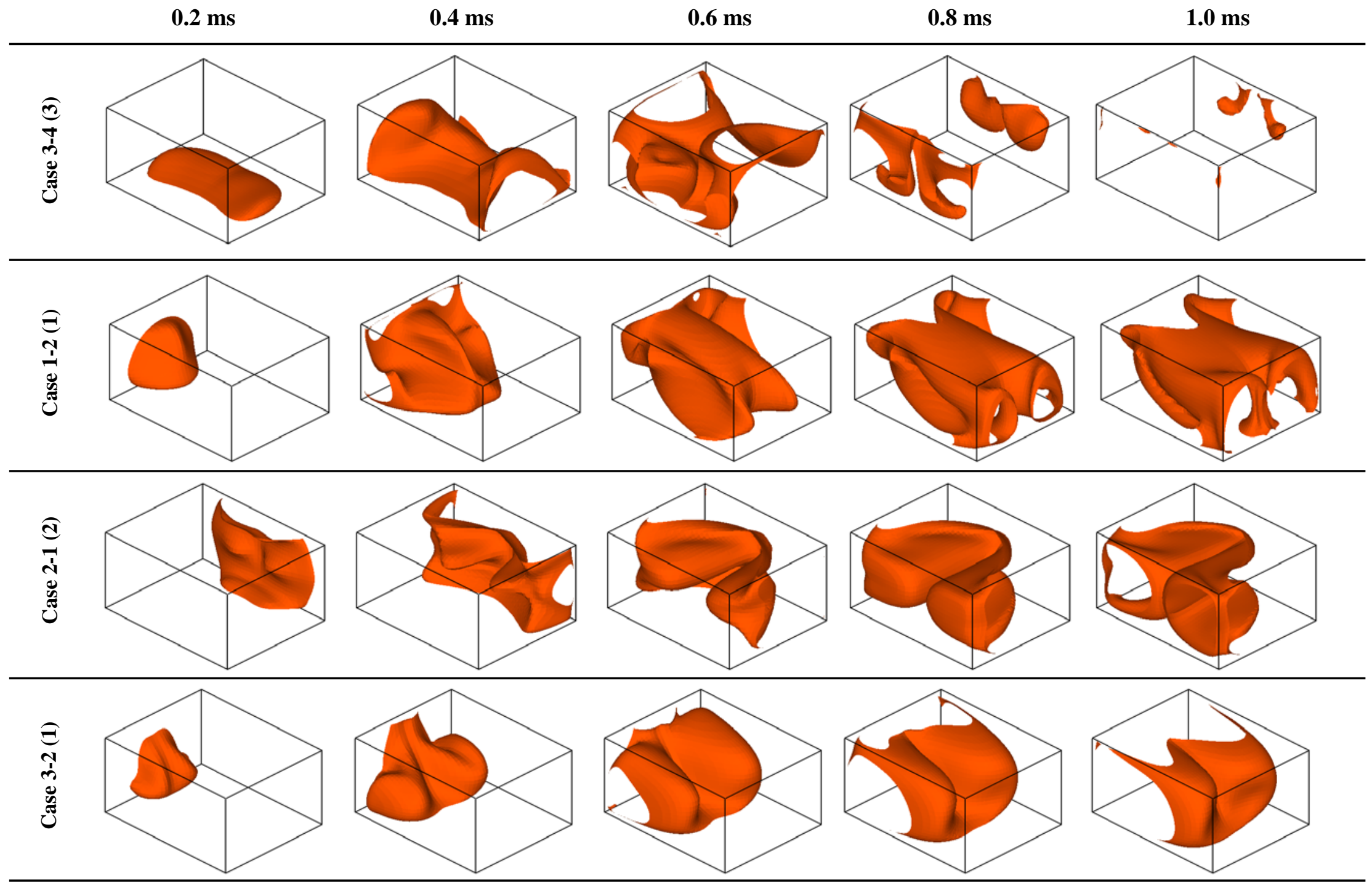

Figure 13. Flame surface vs. time for four representative configurations, ranging from fastest case (top) to slowest case (bottom), revealing major phenomena affecting overall combustion time scale. 

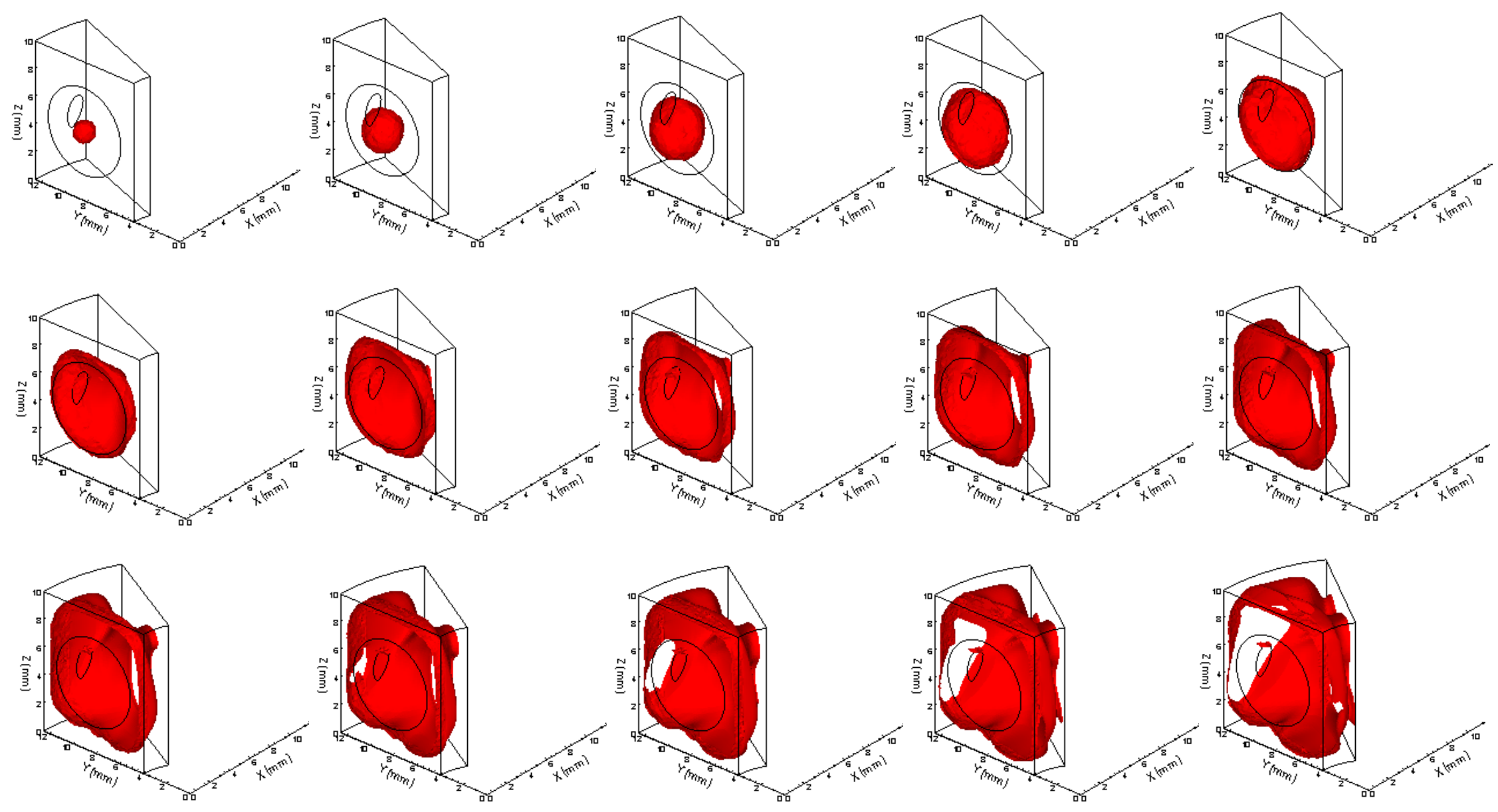

(See caption on following page) 

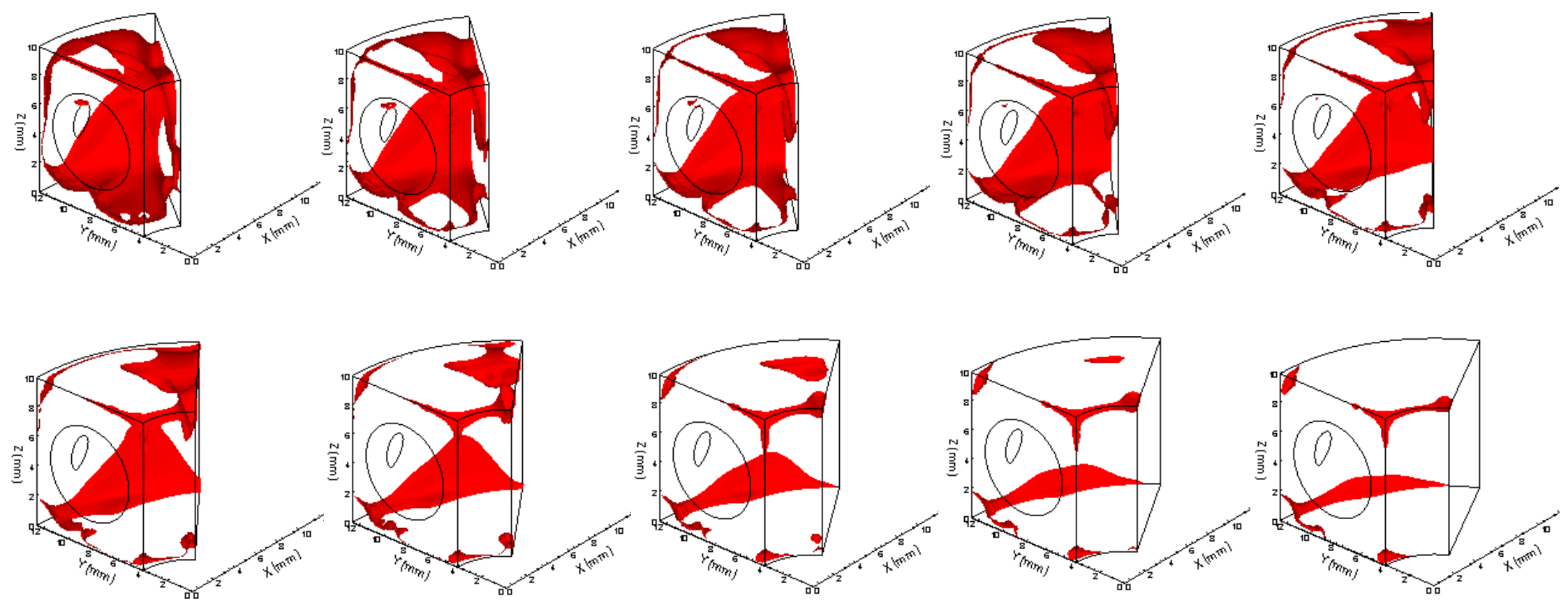

$2.4 \mathrm{~ms}$

Figure 14. Computed flame front propagation in actual swing engine combustion chamber for zero spark advance time and side-injection configuration (shown every $0.1 \mathrm{~ms}$ ), showing that the present $G$-equation model has the capability of simulating flame propagation in real combustion chamber. 
energy at the moment when combustion is initiated is $0.97 \mathrm{~m}^{2} / \mathrm{s}^{2}, 3.45 \mathrm{~m}^{2} / \mathrm{s}^{2}$ and $6.74 \mathrm{~m}^{2} / \mathrm{s}^{2}$ for the engine running at frequencies of $50 \mathrm{~Hz}, 100 \mathrm{~Hz}$ and $150 \mathrm{~Hz}$. The resulting burned mass fraction profiles for all three cycle frequencies are shown in Fig. 16. The burn time decreases with increasing cycle frequency, which reflects the change in turbulent kinetic energy induced by the motion of the swing arm. This is of great importance for mesoscale internal combustion engines. With decreasing engine size, the Reynolds number associated with the inlet flow decreases and the resulting average turbulent kinetic energy due to the inlet flow decreases as well. The flame thus tends toward propagation at the laminar flame speed. However the linear speed of the moving swing arm in the engine does not change much with decreasing engine size, since the engine frequency and swing arm angular velocity change are inversely proportional to the engine size. The result is that the effect of the swing arm motion on the in-chamber turbulence plays an increasingly more important role for combustion as the engine size decreases. The burned mass fraction profiles vs. scaled time for the three engine frequencies are shown in Fig. 17. It can be seen that there is only a slight difference between them, reflecting the fact that in a swing engine of this size combustion occurs in the mesoscale regime shown in Fig. 1 , where $s \approx s_{T}(k)$.

\section{Conclusions}

Combustion time minimization is essential for maximizing power and efficiency in small-scale internal combustion engines. Unlike true microscale engines, mesoscale engines permit significant mean flow and turbulence patterns to be established by the injection process that can augment flame propagation across the combustion chamber to minimize $\tau_{\boldsymbol{B}}$. The present results have identified features associated with the primary and secondary flows produced by injection at various locations in a generic mesoscale combustion chamber and their effect of the propagation of a premixed flame initiated at various locations relative to the injection site. Mean flow velocities and turbulent flame speeds are found to be comparable in such mesoscale engines, indicating that both the mean flow and turbulence must be matched to the combustion chamber geometry to minimize the overall combustion time $\tau_{B}$. Results show that combustion times in such mesoscale engines can be 8-20 times faster than the laminar combustion time scale $L_{\max } / S_{L}^{0}$ that governs true microscale engines, and can be 1-2 times

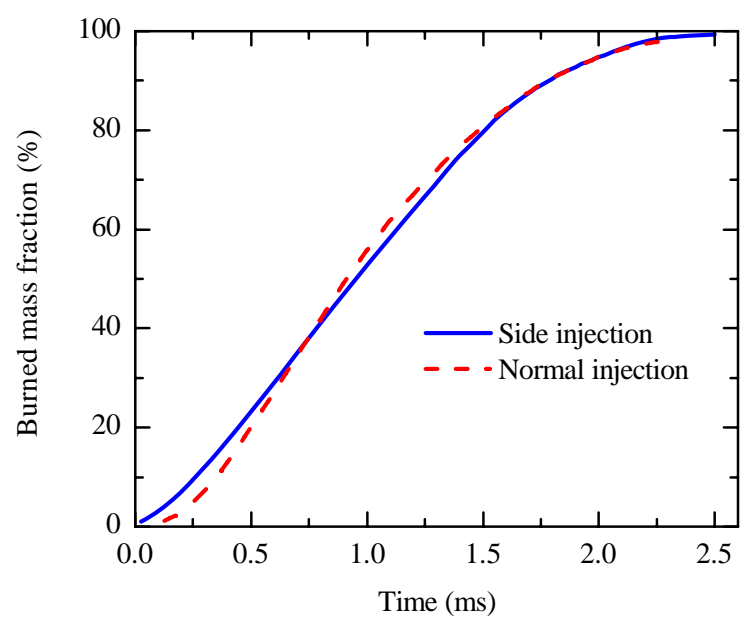

Figure 15. Burned mass fraction profiles vs. time for side injection and normal injection configurations, showing small difference in burn time $\tau_{\mathrm{B}}$.
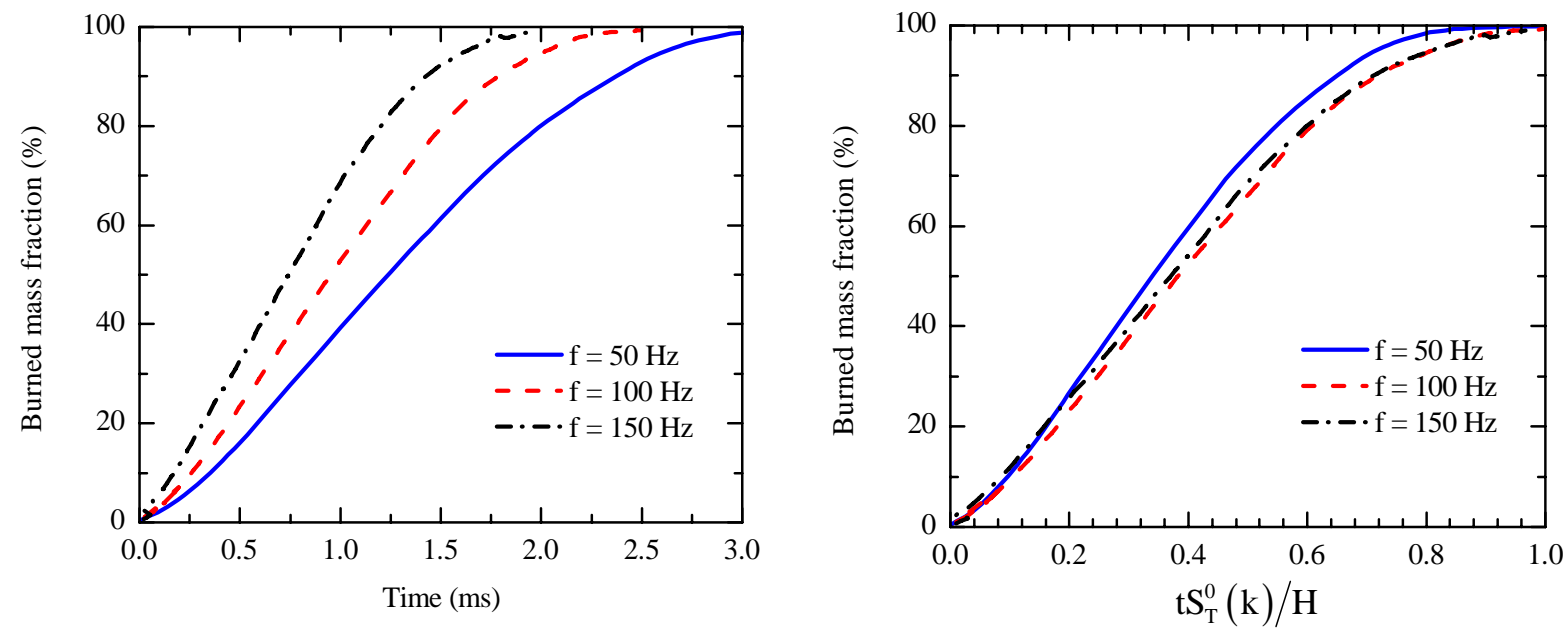

Figure 16. Burned mass fraction profiles vs. time for three engine frequencies, showing reduction in burn time $\tau_{\mathrm{B}}$ with increasing in engine frequency.

Figure 17. Burned mass fraction profiles vs. scale time for three engine frequencies. 
faster than the turbulent combustion time scale $L_{\max } / S_{T}^{0}$. Minimum $\tau_{B}$ values are found to result from the injection across the smallest chamber dimension, with ignition located directly opposite, to provide rapid initial flame growth and a secondary flow that assists in flame propagation. The resulting minimum combustion time can lead to dramatically higher power and efficiency characteristics in such mesoscale engines.

The numerical results for flame propagation in a realistic mesoscale internal combustion swing engine also shows that the combustion is in the regime of mesoscale combustion as shown in Fig. 1 and the combustion time is determined by mean turbulent kinetic energy. The increase of mean turbulent kinetic energy leads to short combustion time and hence better engine performance. The numerical simulation also shows that the turbulence induced by the motion of the moving component can enhance in-chamber turbulence and therefore reduce combustion time.

\section{Acknowledgment}

This work was supported by the Defense Advanced Research Projects Agency (DARPA) Defense Sciences Office (DSO) Palm Power Program under Contract No. MDA972-01-1-0031, with Dr. Valerie Browning and Dr. Robert J. Nowak as Program Managers.

\section{References}

1. Epstein, A.H., Senturia, S.D., Al-Midani, O., Anathasuresh, G., Ayon, A., Breuer, K., Chen, K.-S., Ehrich, F.F., Esteve, E. and Frechette, L. Micro-Heat Engines, Gas Turbines, and Rocket Engines - the Mit Microengine Project AIAA Paper 97-1773. AIAA, Washingtion, D.C. 1997.

2. Spadaccini, C.M., Mehra, A., Lee, J., Zhang, X., Lukachko, S. and Waitz, I.A., High Power Density Silicon Combustion Systems for Micro Gas Turbine Engines. Journal of Engineering for Gas Turbines and PowerTransactions of the Asme, 2003. 125(3): p. 709-719.

3. Fernandez-Pello, A.C., Micropower Generation Using Combustion: Issues and Approaches. Proceedings of the Combustion Institute, 2003. 29: p. 883-899.

4. Aichlmayr, H.T., Kittelson, D.B. and Zachariah, M.R., Miniature Free-Piston Homogeneous Charge Compression Ignition Engine-Compressor Concept - Part I: Performance Estimation and Design Considerations Unique to Small Dimensions. Chemical Engineering Science, 2002. 57(19): p. 4161-4171.

5. Aichlmayr, H.T., Kittelson, D.B. and Zachariah, M.R., Micro-Hcci Combustion: Experimental Characterization and Development of a Detailed Chemical Kinetic Model with Coupled Piston Motion. Combustion and Flame, 2003. 135(3): p. 227-248.

6. Mehra, A., Zhang, X., Ayon, A.A., Waitz, I.A. and Schmidt, M.A., Through-Wafer Electrical Interconnect for Multilevel Microelectromechanical System Devices. Journal of Vacuum Science \& Technology B, 2000. 18(5): p. 2583-2589.

7. Fu, K., Martinez, A.J.K.F.C., Walther, D.C., Fernandez-Pello, C., Pisano, A.P., Liepmann, D., Miyaska, K. and Maruta, K. Design and Experimental Results of Small-Scale Rotary Engines.ASME International Mechanical Engineering Congress and Exposition. New York. 2001.

8. Dahm, W.J.A., NI, J., Mijit, K., Mayor, R., Qiao, G., Benajmin, A., Gu, Y., Lei, Y., Papke, M. and Wu, S.M. Micro Internal Combustion Swing Engine (Micse) for Portable Power Generation Systems AIAA Paper 2002-0722. AIAA, Washington, D.C. 2002.

9. Annen, K.D., Stickler, D.B. and Woodroffe, J. Linearly-Oscillating Miniature Internal Combustion Engine (Mice) for Portable Electric Power.41st Aerospace Sciences Meeting and Exhibit. Reno, Nevada. 2003.

10. Williams, F.A.Siam Journal on Applied Mathematics. Philadelphia. 1985.

11. Bray, K.N.C. and Moss, J.B., Unified Statistical-Model of Premixed Turbulent Flame. Acta Astronautica, 1977. 4(3-4): p. 291-319.

12. Marble, F.E. and Broadwell, J.E., The Coherent Flame Model for Turbulent Chemical Reactions. 1977, Project SQUID, Technical Report TRW-9-PU.

13. Peters, N., Turbulent Combustion. 2000: Cambridge University Press.

14. Dekena, M. and Peters, N., Combustion Modeling with the G-Equation. Oil \& Gas Science and Technology- Rev. IFP, 1999. 54(2): p. 265-270.

15. Tan, Z.C. and Reith, R.D. Modeling Ignition and Combustion in Spark-Ignition Engines Using a Level Set Method. 2003-01-0722.

16. Abraham, J., Williams, F.A. and Bracco, F.V., A Discussion of Turbulence Flame Structure in Premixed Charges. SAE paper, 1985(850345).

17. Shu, C.W. and Osher, S., Efficient Implementation of Essentially Non-Oscillatory Shock-Capturing Schemes .2. Journal of Computational Physics, 1989. 83(1): p. 32-78. 
18. Sussman, M. and Fatemi, E., An Efficient, Interface-Preserving Level Set Redistancing Algorithm and Its Application to Interfacial Incompressible Fluid Flow. Siam Journal on Scientific Computing, 1999. 20(4): p. 1165-1191.

19. Barth, T.J. and Jespersen, D.C.AIAA-89-0366. 1989.

20. Russo, G. and Smereka, P., A Remark on Computing Distance Functions. Journal of Computational Physics, 2000. 163(1): p. 51-67.

21. Peters, N., The Turbulent Burning Velocity for Large-Scale and Small-Scale Turbulence. Journal of Fluid Mechanics, 1999. 384: p. 107-132.

22. Kee, R.J., Grcar, J.F., Smooke, M.D. and Miller, J.A., A Fortran Program for Modeling Steady Laminar OneDimensional Premixed Flames. 1985, Sandia National Laboratories.

23. Bowman, C.T., Hanson, R.K., Davidson, D.F., Gardiner, W.C., Lissianski, V., Smith, G.P., Golden, D.M., Frenklach, M. and Goldenberg, M., Http://Www.Me.Berkeley.Edu/Gri_Mech/.

24. Echekki, T. and Mungal, M.G., Partical Tracking in a Laminar Premixed Flame. Physics of Fluids, 1990. 2(9). 